\title{
Spatio-Temporal Assessment of Climate in Response to Solar Radiation Changes over Nigeria Using Satellite Data
}

\author{
Abiem Louis Tersoo, Igbawua Tertsea*, Aondoakaa Solomon Igbalumun \\ Department of Physics, University of Agriculture, Makurdi, Nigeria \\ Email address: \\ lotabiem@gmail.com (A. L. Tersoo), talk2tertsee@yahoo.com (I. Tertsea), talk2igbalumun@yahoo.com (A. S. Igbalumun) \\ ${ }^{*}$ Corresponding author
}

\section{To cite this article:}

Abiem Louis Tersoo, Igbawua Tertsea, Aondoakaa Solomon Igbalumun. Spatio-Temporal Assessment of Climate in Response to Solar Radiation Changes over Nigeria Using Satellite Data. International Journal of Energy and Environmental Science.

Vol. 5, No. 2, 2020, pp. 40-46. doi: 10.11648/j.ijees.20200502.12

Received: January 10, 2020; Accepted: February 4, 2020; Published: May 19, 2020

\begin{abstract}
Spatiotemporal assessment of climate elements in response to solar radiation changes is vital for understanding the interaction between solar energy budget and climate over Nigeria. In this work, the spatio-temporal assessment of climate changes in response to solar radiation budget was done using regression and correlation analysis on satellite remote sensing and gridded observation data. The satellite data sets include; the Top Net Solar radiation data, obtained from European Medium Range Weather Forecast Reanalysis version 5 data set (ERA5) and Extended Reconstructed Sea Surface (ERSST) data set. The gridded observation climate data sets were obtained from Climate Research Unit (CRU) of University of East Anglia. The 250 x $250 \mathrm{~m}$ Digital Elevation data sets were obtained from Shuttle Radar Topographic Mission (SRTM). Results showed the Top net solar radiation $\left(\mathrm{J} / \mathrm{m}^{2}\right)$, precipitation and temperature indicated trends (Rsquare values) of $8643.9(0.08),-0.287(0.06)$ and $0.019(0.26)$ per year respectively. The correlation between Top net radiation and temperature shows, 7, 2 and $91 \%$ pixels to be negatively, zero and positively correlated while the correlation between Top net radiation and precipitation shows, 71,8 and 21\% pixels respectively to be negatively, zero and positively correlated. Results shows that there was no direct relationship between Elnino Southern Oscillation (ENSO) but arguably, temperature showed indirect relationship with Top net solar radiation. Also, residual analysis was applied to delineate areas that have no direct relationship between radiation and climate parameters.
\end{abstract}

Keywords: Climate Change, Nigeria, Solar Radiation, Residual Trends, ENSO

\section{Introduction}

Energy is essential for the economic and sociodevelopmental activities of humans. This has made power generation one of the major challenges faced by humans in the $21^{\text {st }}$ century, as the dependence on conventional energy (fossil fuel and nuclear reactors) sources of power generation tend to poise threats to human safety and existence. While developed countries of the world are fighting the impact of excessive use of these fossil fuels, the developing ones are faced with inadequate, inefficient and unreliable energy supply. The International Energy Agency stated in 2014 that about 620 million people living in sub Saharan Africa have no access to electricity, and the supply is inadequate, costly and unreliable for the few who have it. It also estimated that about 730 million people in the
African region depend on biomass for cooking and heating, which is responsible for air pollution that results in large number of deaths on a yearly base [1]. Apart from that, the use of wood as a fuel source also leads to the continuous falling of trees that causes desert encroachment, erosion and loss of soil fertility, which in turn affects climatic conditions. This has made the continent of Africa most vulnerable to the impacts of climate changes [2].

Solar energy is harnessed both by photovoltaic (PV) solar system which directly convert solar radiation into electrical energy and by the use of solar thermal systems [3]. The PV solar system is the fastest growing renewable energy in Nigeria [4] and in the whole world [5].

The variability in the amount of solar radiation received 
on the Earth's surface is of implicit significance to climate changes both at a global, regional and local scales. It is also of importance for water resources, agriculture, architectural design and solar thermal devices [6]. Solar energy has direct effects on many physical, chemical and biological cycles [7]. According to Bazyomo et al, 2016, the most important varying parameters in solar energy are solar irradiance and ambient temperature [8]. Changes in solar radiation intensity are proportionate to PV power output, whereas increase in ambient temperature tends to negatively affect the performance of the PV panels. A good understanding of climate changes and projected trends of these variables is of outmost importance in policymaking and industrial management in undertaking the installation of solar cells in a particular location.

Furthermore, variations in global solar radiation and rainfall to a large extent determines the weather condition of a place, and may lead to the formation of pollutants in the atmosphere by photochemical processes derived from chemical precursors [9]. The relationship between solar irradiance and rainfall also reflects the behaviour of largescale phenomena like the El Niño-Southern Oscillation (ENSO), which can modify the normal conditions of the atmosphere in several regions of the earth, altering local weather patterns.

At the global scale, some researchers assessed changes in surface solar irradiance in the $20^{\text {th }}$ century by measurements and through simulations. The analysis of the $20^{\text {th }}$ Century simulations was done with climate models and their results showed that all the models estimated a global annual mean reduction in surface solar radiation of $1-4 \mathrm{~W} / \mathrm{m}^{2}$ while the globe warms by $0.4-0.7^{\circ} \mathrm{C}[10]$.

Bazyomo et al., 2017 carried out a study to analyse the energy output considering the impact of climate changes, variability and trends of solar radiation intensity and surface air temperature [11]. They results showed that the trends of solar irradiation are negative and photovoltaic power output was estimated to reduce in all parts of West Africa. Research conducted in Ethiopia checked trends and variability of rainfall and temperature in some regions and showed an increasing trend of annual maximum, minimum and mean temperature. An increase of $1.08^{\circ} \mathrm{C}$ was observed [12]. Trend analysis of mean annual temperature was also carried out in Rwanda for fifty-two years. The results showed a significant warming trend over the period between 1977 and 1979 with Kigali the capital showing the highest values [13].

Considering the scanty research situation in Nigeria, the work aims at giving a more detailed and updated analysis of the changes in Top Net Solar Radiation (TNSR) in relation with climate and ENSO signals over Nigeria from 1988 to 2015. Most analyses covering Nigeria did not report on spatial and temporal changes using long term data sets. There is a need to understand the spatio-temporal changes in TNSR in response to climate records whether they indicate any different relationship between TNSR and climate; how TNSR and climate variables fluctuate from their mean position in different ENSO years too. Thus, the specific objectives of this research are to: (1) study spatio-temporal changes in TNSR and climate from 1988 to 2015; (2) analyse the seasonal, monthly and yearly time series of TNSR and climate; (3) assess the TNSR-climate anomalies as well as the sea surface temperature (SST) anomalies over Nigeria from 1988 to 2015.

\section{Materials and Methods}

\subsection{Study Area}

Nigeria is located in Africa and comprises of about 36 states. The country is the most densely populated region in West Africa which is located in between the dry Sahel and desert to the north and the Atlantic Ocean to the south. Nigeria is located at latitudes $4^{\circ}-14^{\circ} \mathrm{N}$ and longitude $2^{\circ} \mathrm{W}-$ $14^{\circ}$ East, covering an area of about $923,769 \mathrm{~km}^{2}$ [14]. The vegetation zones include; forest, guinea, Sudan and Sahel savannah. There are two basic rivers in Nigeria; the Benue and Niger rivers. There are a lot of river networks in Nigeria, most settlements are located at the banks of some rivers or streams. The rainfall distribution in the forest and guinea savannah regions is higher than the dry Sahel. Figure 1 is the geographical map of Nigeria, showing its location on the African map.

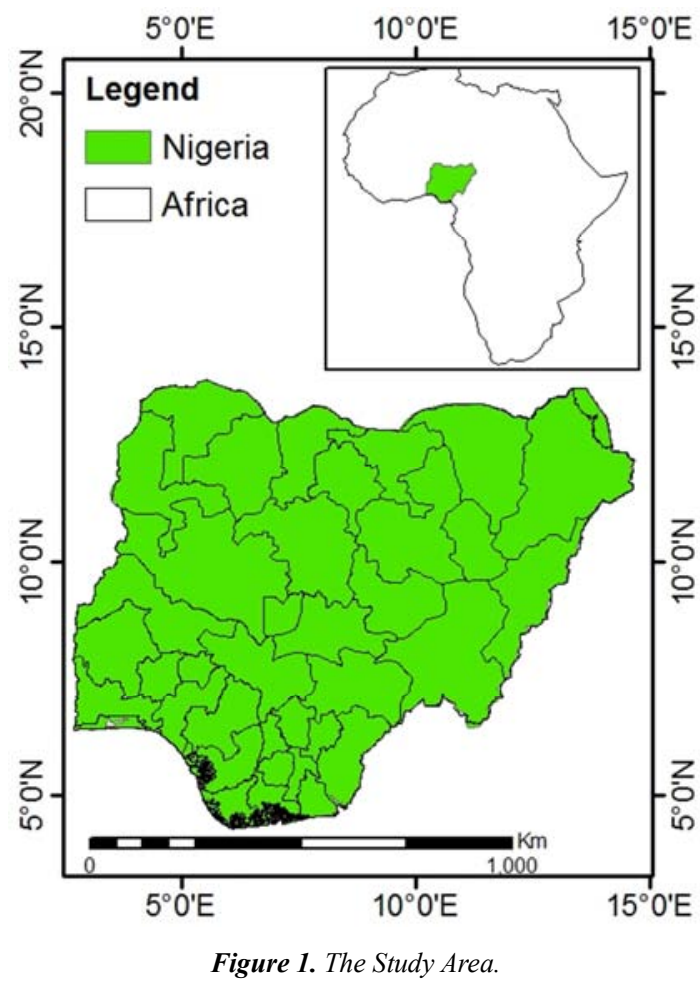

\subsection{Data Sets}

The data used in this work include; Gridded observation (precipitation and temperature) data from climate Research Unit (CRU) of University of East Anglia and European Centre for Medium Range Weather Forecast Reanalysis version 5 (ERA5) data sets (Top Net Solar Radiation) from 1988 to 2015. The Gridded observation 
data (CRU) and satellite remote sensing (ERA) data records were obtained at $0.5^{\circ} \times 0.5^{\circ}$ and $0.25^{\circ} \times 0.25^{\circ}$ respectively and re-gridded to $0.083^{\circ} \times 0.083^{\circ}$ spatial resolution. The CRU gridded data records have been widely applied in many studies globally and over Africa. CRU gridded observation data is arguably the most suitable climate data sets for a country like Nigeria as a result of the fact that the region is data sparse.

The Extended Reconstructed Sea Surface Temperature version 4 (ERSSTv4) temperature data are very helpful in studying ENSO effects globally. In this work, the data records were used to study the ENSO effects in Elnino, Lanina and Neutral years. The data records were retrieved from https://www1.ncdc.noaa.gov/pub/data/cmb/ersst/v5/. The El-nino Southern Oscillation (ENSO) signal is determined via a number of indicators from the Pacific Ocean which include the Pacific Sea Surface Temperature (SST), Southern Oscillation Index (SOI) or Outgoing longwave radiation. Southern Oscillation Index (SOI) is referred to as the sea level pressure (SLP) [15].

\subsection{Methods}

The following methods were adopted in this work.

\subsubsection{Regression Analysis}

The Ordinary Least Square regression analysis was used in this work. It is given by equation 1 .

$$
y=\alpha+\beta x+\gamma
$$

where $y$ is the dependent variable, in this case Top Net Solar Radiation. $x$ is the independent variable i.e. precipitation and temperature. $\alpha$ is the intercept and $\gamma$ the error term.

$\beta$ which is the regression slope is given as

$$
\beta=\frac{\sum(y-\bar{y}) \cdot(x-\bar{x})}{\sum(x-\bar{x})^{2}}
$$

where $y$ and $x$ are the predictor and response variables respectively

\subsubsection{Residual Trend Analysis}

The Residual trend analysis is a method that examines the trend (slope) of the residual differences between the observed Top net solar radiation and the predicted Top net solar radiation (TNSR) using linear regression model with either precipitation or temperature [16].

These steps were followed

(i) Firstly, a regression model between the observed TNSR and precipitation or temperature assessed at pixel level.

(ii) Secondly, the residuals obtained as the difference between the observed and the predicted TNSR from the linear model is computed and recorded as residuals.

(iii) Thirdly, another linear regression of the residuals against time is done to obtain the trends. The trends are interpreted as changes in Top net solar radiation that are not dependent of precipitation or temperature.

\subsubsection{Correlation Analysis}

The Pearson correlation analysis is given as

$$
\operatorname{Cor}_{x y}=\frac{\sum(y-\bar{y}) \cdot(x-\bar{x})}{\sum \sqrt{(y-\bar{y})^{2} \cdot \sum \sqrt{(x-\bar{x})^{2}}}}
$$

where $y$ and $x$ are the 2 parameters respectively.

\section{Results}

Figure 2 shows the annual values and trends in (a) TNSR (b) precipitation and (c) Temperature. Results showed the Top net solar radiation $\left(\mathrm{J} / \mathrm{m}^{2}\right)$, precipitation and temperature indicated trends (R-square values) of 8643.9 (0.08), -0.287 $(0.06)$ and $0.019(0.26)$ per year respectively
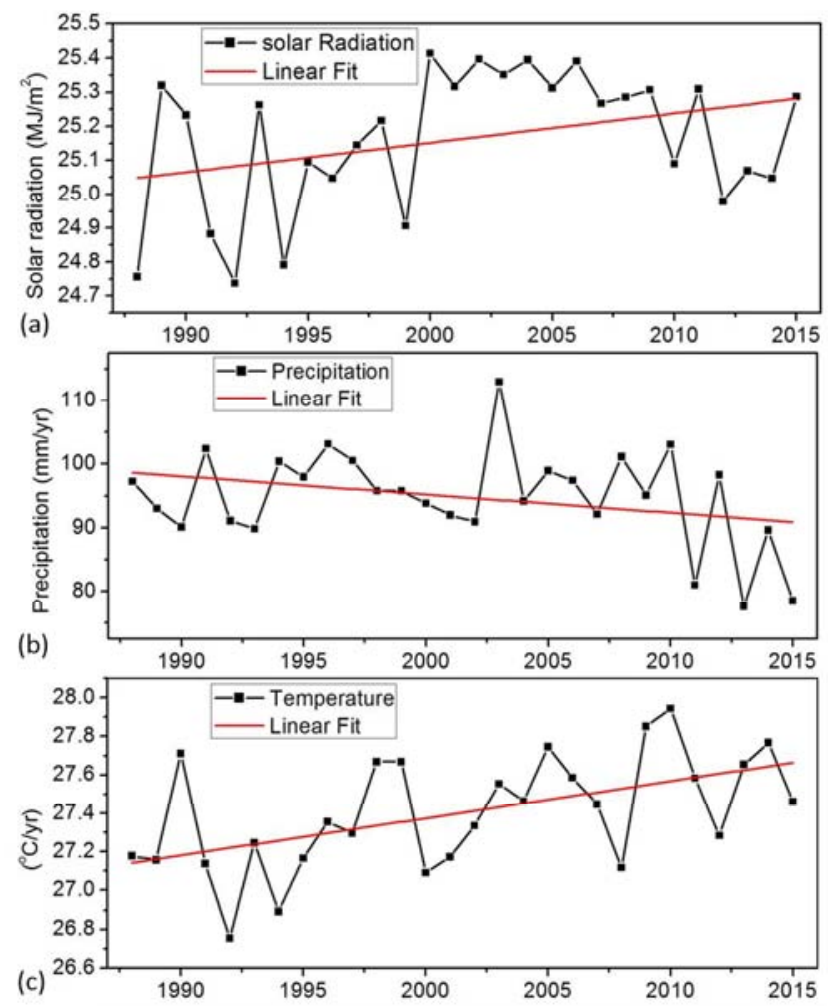

Figure 2. Slope of (a) TNSR, (b) precipitation and (c) temperature.

Figure 3 shows the seasonal average values for TNSR and climate elements. In Figure 3 (a), lowest values of TNSR $\left(\mathrm{MJ} / \mathrm{m}^{2}\right)$ were observed during the peak rainy season months from July to August. The annual seasonal precipitation of the study area in July, August and September from 1988 to 2015 is over $200 \mathrm{~mm} / \mathrm{yr}$. From figure 3 (a) and 3 (c), the dry season months recorded higher TNSR and ground surface warming than the wet season months. This indicates that dry season months are most favourable for solar energy harvesting than the wet season months. 

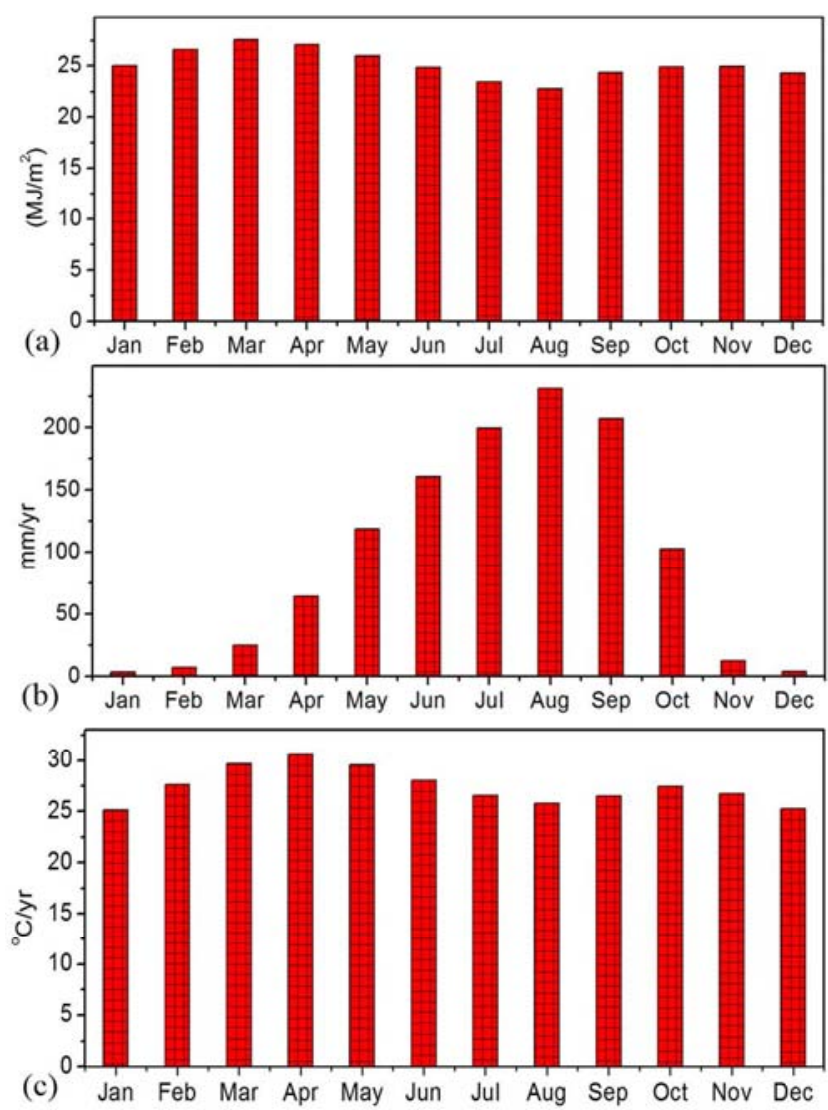

Figure 3. Seasonal (a) Top net solar radiation (b) precipitation and (c) temperature averaged from 1988 to 2015.

From figure 4, standardized anomalies were computed to show above/below average conditions in TNSR and climate parameters from 1988 to 2015. Result shows both TNSR and temperature have shown above average conditions in Top net solar radiation and surface air warming. This is an indication climate change is rather favouring renewable energy production from solar radiation.

Table 1 shows value of Pearson correlation coefficient between TNSR and climate elements from 1988 to 2015. Correlation between TNSR and precipitation shows negative values which are statistically insignificant for rainy season months from June to September. Also, negative values which are statistically significant were obtained for end of growing season October to November and dry season months from December to April. The highest (lowest) correlation coefficient was observed in December (-0.751), February (-0.738) and April (-0.736).

Figure 5 (a) and 5 (b) shows that the correlation between Top net radiation and temperature shows, 7, 2 and $91 \%$ pixels to be negatively, zero and positively correlated while the correlation between Top net radiation and precipitation shows, 71,8 and $21 \%$ pixels respectively to be negatively, zero and positively correlated.
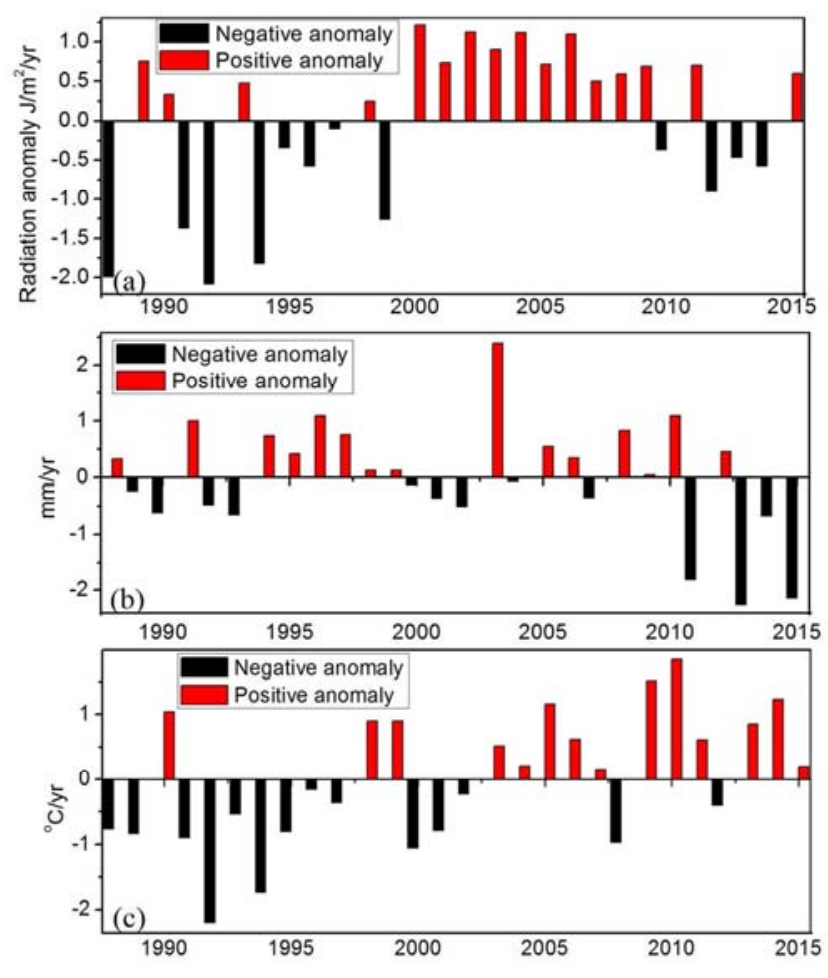

Figure 4. Standardize Anomalies in (a) TNSR (b) precipitation and (c) temperature averaged from 1988 to 2015.
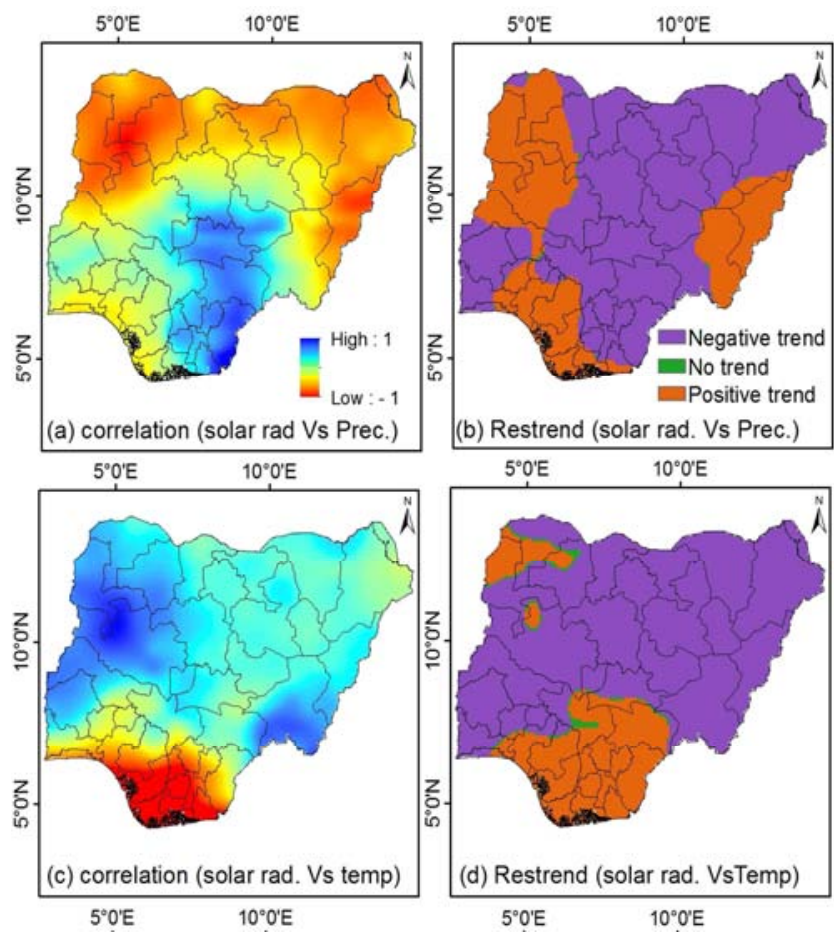

Figure 5. (a) Pearson spatial correlation coefficient between Top net solar radiation and precipitation (b) Residual Trend analysis between TNSR and precipitation (c) and (d) are Pearson correlation coefficient and Residual Trend analysis for temperature respectively.

In Figure 5 (c) and 5 (d), the residual trend analysis has been computed for regression between TNSR versus precipitation and solar radiation versus temperature using equation 1 . After obtaining the residuals, another regression was performed on 
the residuals and the trends of the residuals were obtained. Generally, regression models with large residuals indicate large deviations from the model. The positive trends are interpreted as changes in TNSR that are not dependent of precipitation and temperature. Thus areas that precipitation showed no response to TNSR over the study region include parts of North-west, North-central, South-west, South-south and South-east. Similarly, areas that temperature showed no response to TNSR over the study region include parts of North-central, South-South South-west and South-east

Table 1. Correlation between TNSR versus climate.

\begin{tabular}{lll}
\hline Month & TNS Vs. precipitation & TNS Vs. temperature \\
\hline Jan & $-0.449^{*}$ & $-0.411^{*}$ \\
Feb & $-0.738^{*}$ & $0.667^{*}$ \\
Mar & $-0.689^{*}$ & -0.372 \\
Apr & $-0.736^{*}$ & -0.111 \\
May & $-0.481^{*}$ & 0.392 \\
Jun & -0.242 & 0.399 \\
Jul & -0.325 & 0.544 \\
Aug & -0.141 & 0.736 \\
Sep & -0.369 & 0.780 \\
Oct & $-0.575^{*}$ & 0.043 \\
Nov & $-0.481^{*}$ & $-0.618^{*}$ \\
Dec & $-0.751^{*}$ & -0.474 \\
\hline
\end{tabular}

(*shows statistical significance at 5\% sig. Level).

Figure 6 shows the Pearson correlation coefficient between TNSR and climate elements. Result shows that latitudinal variations have also been found for the solar response in climate elements over Nigeria. Correlation between TNSR and precipitation shows high values at lower latitudes with low at the higher latitudes. This suggests that precipitation responds well to TNSR at lower latitudes than higher latitudes. Similarly, correlation between TNSR and temperature shows low values at lower latitudes with high values at the higher latitudes. This suggests that temperature responds best with TNSR at higher latitudes than lower latitudes.

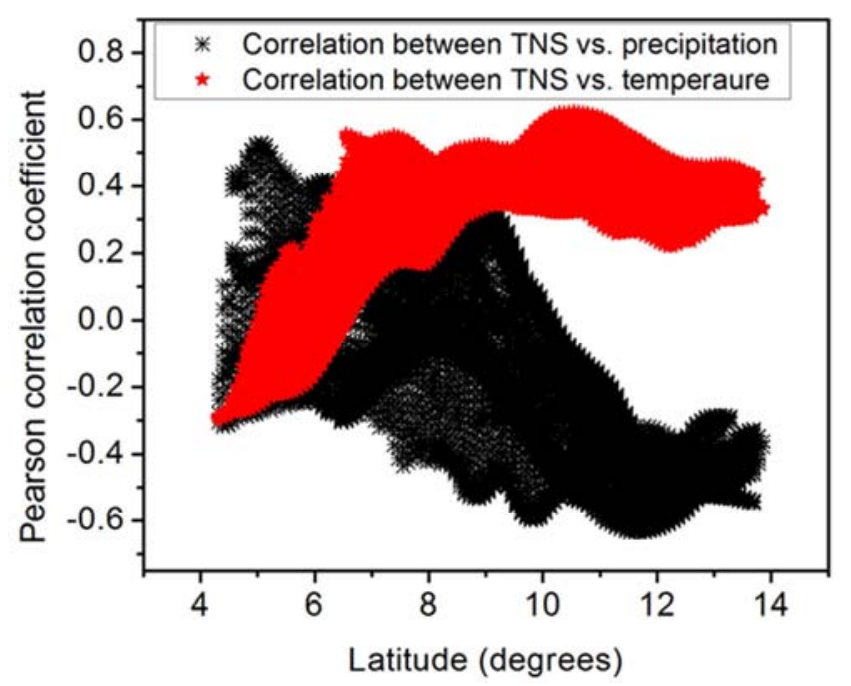

Figure 6. Pearson Correlation coefficient between TNSR and climate elements at different latitude.
The research work considered El Niño, neutral, and La Niña years from sea surface temperature (SST) anomalies of the tropical Atlantic ocean. A range from $+0.5^{\circ} \mathrm{C}$ and $-0.5^{\circ} \mathrm{C}$ also known as the Niño 3.4 region was adopted and the gridded Extended Reconstructed Sea Surface Temperature version 4 (ERSSTv4) temperature data was used to extract the SST values [17]. The work considered average SST anomalies exceeding $>+0.5^{\circ} \mathrm{C}$ as El Niño, $<-0.5^{\circ} \mathrm{C}$ as La Niña, and from $-0.5^{\circ} \mathrm{C}$ to $+0.5^{\circ} \mathrm{C}$ as Neutral years respectively [18]. Table 2 shows the El Niño, La Niña and Neutral years extracted from ERSSTv4. The correlation between TNSR and climate elements in El Niño, La Niña and Neutral years is shown in table 3 .

Figure 7 shows standardized anomalies used in extracting the ENSO events. The blue dotted line demarcates the neutral years from the cool and warm phases of ENSO. Result from table 2 shows 11, 10 and 7 warm, neutral and cool years respectively. This shows dominance of warmer years in the last 2 decades. Table 3 shows the correlation between TNSR and climate in different ENSO event. Results indicates a statistically insignificant negative correlation and positive correlation for precipitation and temperature respectively. This results shows that there are no direct impacts of ENSO on the relationship between TNSR and climate especially for precipitation.

Table 2. Extraction of El Niño, Neutral, and La Niña years between from 1988 to 2015 using ERSSTv4 SST anomalies.

\begin{tabular}{lll}
\hline EI nino years (11) & Neutral years (10) & La nina years (7) \\
\hline 1997 & 1988 & 1989 \\
1998 & 1990 & 1991 \\
2003 & 1993 & 1992 \\
2004 & 1994 & 1995 \\
2006 & 1999 & 1996 \\
2007 & 2000 & 2001 \\
2008 & 2002 & 2011 \\
2009 & 2005 & \\
2010 & 2013 & \\
2012 & 2014 & \\
2015 & & \\
\hline
\end{tabular}

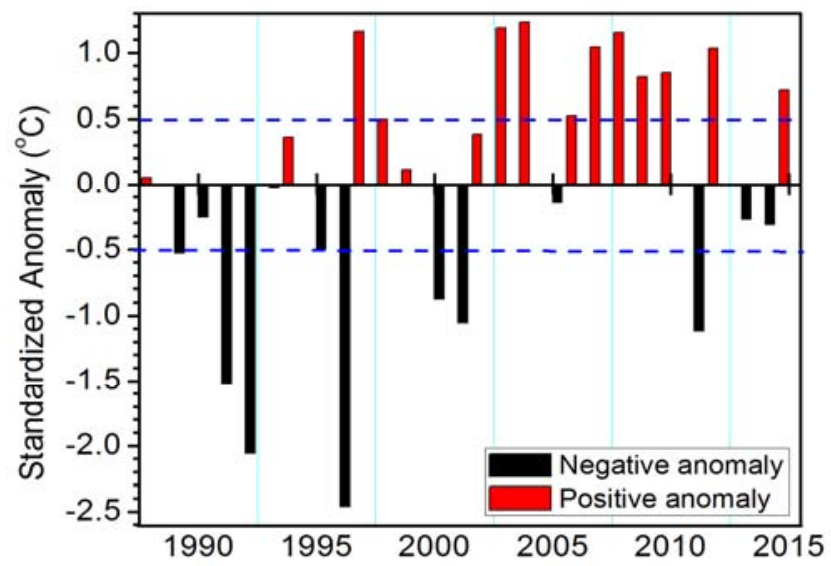

Figure 7. Standardized anomalies in Sea surface temperature from 1988 to 2015 showing ENSO events. 
Table 3. Correlation between TNSR versus climate in different ENSO event ( $*$ shows statistical significance at $5 \%$ sig. Level).

\begin{tabular}{lll}
\hline Month & TNSR Vs. precipitation & TNSR Vs. temperature \\
\hline Elnino & -0.606 & 0.273 \\
Neutral & -0.102 & 0.062 \\
Lanina & -0.290 & 0.382 \\
\hline
\end{tabular}

\section{Conclusion}

In this work, the spatio-temporal assessment of climate changes in response to solar radiation budget was done using regression and correlation analysis using satellite remote sensing and gridded observation data from 1988 to 2015.

Results showed the Top net solar radiation $\left(\mathrm{J} / \mathrm{m}^{2}\right)$, precipitation and temperature indicated trends (R-square values) of $8643.9(0.08),-0.287(0.06)$ and $0.019(0.26)$ per year respectively.

Correlation between TNSR and precipitation shows negative values which are statistically insignificant for rainy season months from June to September while negative values which are statistically significant were obtained for end of growing season October to November and dry season months from December to April. The highest (lowest) correlation coefficient was observed in December $(-0.751)$, February (0.738) and April (-0.736).

The correlation between Top net radiation and temperature shows, 7, 2 and $91 \%$ pixels to be negatively, zero and positively correlated while the correlation between Top net radiation and precipitation shows, 71,8 and $21 \%$ pixels respectively to be negatively, zero and positively correlated.

The results shows that there was no direct relationship between Elnino Southern Oscillation (ENSO), but arguably, temperature and precipitation showed indirect relationship with Top net solar radiation.

To this extent, the study is relevant to policy makers and it provides the necessary information that is helpful for local energy planning and disaster risk mitigation in the face of a vulnerable eco-climatic system set out by a varying climate system over Nigeria as well as West Africa.

It is recommended that the study be extended to cover a period longer than the 27 years (1988 to 2015) covered in this work. Also more weather parameters other than precipitation and temperature covered by this work could be used to study the interaction between solar energy budget and climate over Nigeria.

\section{References}

[1] International Energy Agency, World Energy Outlook, 2014, OECD/ IEA: CORLET Paris cedex France.

[2] Smith, K. R.; Woodward, A.; Campbell-Lendrum, D.; Chadee, D. D.; Honda, Y.; Liu, Q.; Olwoch, J. M.; Revich, B.; Sauerborn, R., Climate Change: Impacts, Adaptation, and Vulnerability. 2014, Part A: Global and Sectoral Aspects. Contribution of Working Group II to the $5^{\text {th }}$ Assessment Report of the Intergovernmental Panel on Climate Change: Cambridge, UK; New York, NY, USA, pp. 709-754.
[3] Morales-Salinas, L.; Cárdenas-Jirón, L. A.; GonzálezRodríguez, E., A Simple Physical Model to Estimate Global Solar Radiation in the Central Zone of Chile; 2007, Dept of Environmental Sciences and Natural Renewable Resources, Faculty of Agronomy, Univ. of Chile: Santiago, Chile.

[4] Sambo, A. S., Bala, E. J., Penetration of Solar Photovoltaic into Nigeria's Energy supply mix. in World Renewable Energy Forum (WREF). 2012, Denver, Colorado USA: Curran Association Inc.

[5] Breyer, C.; Schmid, J., Population Density and Area weighted Solar Irradiation: Global Overview on Solar Resource Conditions for fixed tilted, 1-axis and 2-axes PV Systems. In Proceedings of the 25th European PV Solar Energy Conference and Exhibition, Valencia, Spain; pp. 2019, 46924709 .

[6] Agnidé, E. L., Marc, N. and Célestin, M., Solar Irradiance and Temperature Variability and Projected Trends Analysis in Burundi, 2019, Climate, 7, 83; doi: 10.3390/cli7060083 www.mdpi.com/journal/climate accessed $15^{\text {th }}$ November, 2019.

[7] Fu Q., Solar radiation. In Encyclopedia of Atmospheric Sciences, Holton J, Pyle J, Curry J (eds). Academic Press: Amsterdam; 2003, 1859-1863.

[8] Bazyomo, S. D. Y. B.; Lawin, E. A.; Coulibaly, O.; Ouedraogo, A.; Lawin, A.; Wisser, D., Forecasted Changes in West Africa Photovoltaic Energy Output by 2045. Climate, 2016, 4, 53.

[9] Finlayson-Pitts BJ, Pitts JN Jr., Chemistry of the Upper and Lower Atmosphere: Theory, Experiments, and Applications. Academic Press: San Diego, 2000, CA.

[10] Romanou, A.; Liepert, B.; Schmidt, G. A.; Rossow, W. B.; Ruedy, R. A.; Zhang, Y., 20th century changes in surface solar irradiance in simulations and observations. Geophys. Lett, 34, 2007, 5713-47.

[11] Bazyomo, S. D.; Lawin, E. A.; Ouedraogo, A. Seasonal Trends in Solar Radiation Available at the Earth's Surface and Implication of Future Annual Power Outputs Changes on the Photovoltaic Systems with One and Two Tracking Axes. 2017 J. Clim. Forecast, 5, 1000201.

[12] Birara, H.; Pandey, R. P.; Mishra, S. K., Trend and variability analysis of rainfall and temperature in the Tana basin region, Ethiopia. J. Water Clim. 2018, Chang, 9, 555-569.

[13] Safari, B., Trend analysis of mean annual temperature conduct in Rwanda during fifty two years. Journal of Environmental Protection, 2012, 3, 538-551.

[14] Igbawua, T., Zhang, J., Chang, Q. \& Yao, F. Vegetation dynamics in relation with climate over Nigeria from 1982 to 2011. Environmental Earth Sciences $\mathbf{7 5}$, https://doi.org/10.1007/s12665-015-5106-z (2016).

[15] Stone, R. C., Hammer, G. L. \& Marcussen, T. Prediction of global rainfall probabilities using phases of the Southern Oscillation Index. Nature 384, 252-255. https://doi.org/10.1038/384252a0 (1996).

[16] Ibrahim, Y. Z., Balzter, H., Kaduk, J., and Tucker, C. J. (2015) Land degradation Assessment using residual trend analysis of GIMMS NDVI3g. soil moisture and rainfall in Sub-Saharan West Africa from 1982 to 2012, remote sensing, 5471-5494; doi: $10.3390 /$ rs 70505471 . 
[17] Huang, B., Banzon, V. F., Freeman, E., Lawrimore, J., Liu, W., Peterson, T. C., Smith, T. M., Thorne, P. W., Woodruff, S. D., Zhang, H. M., 2015. Extended reconstructed sea surface temperature version 4 (ERSST. v4). Part I: Upgrades and intercomparisons. J. Clim. 28, 911-930. http://dx.doi.org/10.1175/JCLI-D-14-00006.1.
[18] National Oceanic and Atmospheric Administration, Climate Prediction Center [NOAA CPC] (2015) Cold and Warm Episodes by Season. NOAA Center for Weather and Climate Prediction: College Park, Maryland. Retrieved from: http://www.cpc.ncep.noaa.gov/products/analysis_monitoring/e nsostuff/ensoyears.shtml. Accessed 10/20/19. 